Jumal Sosialisasi

Jurnal Hasil Pemikiran, Penelitian, dan Pengembangan

Keilmuan Sosiologi Pendidikan

Vol 8, Nomor 1, Maret 2021

\title{
PARTISIPASI MASYARAKAT BULUKUMBA DALAM PEMBANGUNAN DAERAH DI KALIMANTAN TIMUR
}

\author{
Muhammad Sultan ${ }^{1}$, Sunardi ${ }^{2}$, Ilham Abu ${ }^{3}$ \\ Universitas Mulawarman, Samarinda, Kalimantan Timur \\ sultan_kajang81@yahoo.co.id
}

\begin{abstract}
ABSTRAK
Kemajuan pembangunan suatu daerah bukan hanya menjadi tanggung jawab pihak pemerintah, akan tetapi dibutuhkan partisipasi secara aktif dari seluruh komponen masyarakat. Kolaborasi yang baik antara pemerintah daerah dan masyarakat merupakan salah satu faktor penting dalam mencapai hal tersebut. Penelitian ini jenis kualitatif deskriptif untuk mendeskripsikan partisipasi masyarakat Bulukumba dalam pembangunan daerah di Kalimantan Timur. Sampel penelitian adalah kepala keluarga atau perwakilan penghuni dalam satu rumah yang berdomisili di Kalimantan Timur sebanyak 60 orang yang dipilih secara Accidental Sampling. Pengumpulan data menggunakan kuesioner secara online dalam bentuk Google form dan disebarkan kepada responden melalui media sosial Whatsapp Group dan dianalisis secara deskriptif serta disajikan dalam bentuk tabel frekuensi dan grafik disertai narasi. Selain itu, untuk memperdalam informasi yang dibutuhkan maka dipilih 3 informan. Teknik pengumpulan informasi melalui wawancara mendalam menggunakan pedoman wawancara kepada informan dan selanjutnya dianalisis secara kualitatif. Hasil penelitian menunjukkan bahwa sebagian besar masyarakat Bulukumba telah berpartisipasi dengan baik dalam pembangunan daerah di Kalimantan Timur. Meskipun demikian, namun masih ditemukan masyarakat Bulukumba yang kurang berpartisipasi dalam pembangunan karena berbagai faktor antara lain kurangnya pemahaman masyarakat tentang pentingnya pembangunan partisipatif. Oleh karena itu, diperlukan kegiatan sosialisasi secara aktif dari pihak pemerintah daerah dan seluruh komponen masyarakat tentang pentingnya partisipasi masyarakat demi terwujudnya pembangunan daerah yang maju dan berkelanjutan.
\end{abstract}

Kata kunci: Partisipasi, Masyarakat Bulukumba, Pembangunan Daerah, Kalimantan Timur.

\begin{abstract}
The progress of the development of a region is not only the responsibility of the government, but requires active participation from all components of society. Good collaboration between local government and communities is an important factor in achieving this. This research is a descriptive qualitative type to describe the participation of the Bulukumba community in regional development in East Kalimantan. The research sample is the head of the family or resident's representative in a house that is domiciled in East Kalimantan, as many as 60 people who were selected by accidental sampling. Collecting data using online questionnaires in the form of Google form and distributed to respondents via Whatsapp Group social media and analyzed descriptively and presented in the form of frequency tables and graphs with narration. In addition, to deepen the required information, 3 informants were selected. The technique of collecting information through indepth interviews uses interview guides to informants and is then analyzed qualitatively. The results showed that most of the people of Bulukumba had participated well in regional development in East Kalimantan. Even so, it was still found that the Bulukumba community did not participate in development due to various factors, including a lack of public understanding of the importance of participatory development. Therefore, it is necessary to have active outreach activities from the local government and all components of society regarding the importance of community participation for the realization of advanced and sustainable regional development.
\end{abstract}

Keywords: Bulukumba Regency; East Kalimantan; Participation; Regional Development. 


\section{PENDAHULUAN}

Masyarakat Sulawesi Selatan sudah dikenal sejak lama di Indonesia hingga luar negeri karena kegigihannya dalam bekerja dan senang merantau. Tidak mengherankan lagi jika hampir setiap daerah di Indonesia dijumpai masyarakat yang berasal dari Sulawesi Selatan (Bachrong, 2020). Kabupaten Bulukumba merupakan salah satu wilayah administratif kabupaten di Sulawesi Selatan. Seperti pada kebanyakan masyarakat Sulawesi Selatan, masyarakat Bulukumba juga dikenal dengan masyarakat yang giat dalam bekerja dan senang bepergian ke daerah lainnya di Indonesia dan keluar negeri dalam waktu singkat atau tinggal sementara dan bahkan tinggal menetap di daerah tujuannya.

Masyarakat Bulukumba yang merantau ke daerah tujuan tertentu tidak dilakukan tanpa tujuan yang jelas. Salah satu tujuan merantau ke daerah tertentu adalah meningkatkan status ekonomi masyarakat (Kassim, 2018) dan memberikan warna baru dalam kehidupan sosial kemasyarakatan (Bachrong, 2020). Selain itu, merantau juga bagi sebagian masyarakat menganggap sebagai media mengkomunikasikan dan memperkenalkan budaya daerah asal didaerah perantauan (Rahim, 2021).

Kalimantan Timur menjadi salah satu daerah tujuan merantau khususnya masyarakat Bulukumba. Letak geografis yang tidak terlalu jauh dari Pulau Sulawesi baik melalui transportasi udara maupun laut sehingga menjadikan Kalimantan Timur menjadi salah satu daerah tujuan perantauan masyarakat Bulukumba. Selain itu, wilayah kabupaten/kota di Kalimantan Timur memiliki potensi sumber daya alam yang melimpah sehingga tentunya memerlukan banyak sumber daya manusia baik dalam pemanfaatan lahan agar produktif secara ekonomi maupun dalam pengelolaannya.

Kondisi perekonomian di Kalimantan Timur periode 2015-2019 didominasi oleh lima kategori lapangan usaha antara lain pertambangan dan penggalian, industri pengolahan, konstruksi, pertanian, kehutanan, dan perikanan perdagangan besar dan eceran, dan reparasi mobil dan motor (Puspitasari, 2020). Pertumbuhan ekonomi berpengaruh terhadap kesejahteraan masyarakat (Tussa'Diah, 2019). Oleh karena itu, kondisi perekonomian suatu daerah yang baik akan berdampak baik pula terhadap kesejahteraan masyarakatnya.

Pada semua sektor pembangunan daerah tidak terlepas dari partisipasi para pelaku ekonomi masyarakat di wilayah tersebut. Pelaku ekonomi berperan penting dalam mendorong perekonomian demi peningkatan pembangunan baik secara nasional maupun daerah (Singgih, 2020). Selain kehadiran masyarakat sebagai faktor penting dalam pembangunan daerah, juga diperlukan kehadiran pihak pemerintah. Pemerintah daerah merupakan salah satu faktor pendukung dan sekaligus dapat menjadi penghambat dalam mendorong partisipasi masyarakat di sektor ekonomi kerakyatan (Arfianto \& Balahmar, 2016).

Sinergi antara masyarakat sebagai pelaku ekonomi dan dukungan pemerintah penting dalam pembangunan dan pengembangan daerah di berbagai sektor pembangunan (Sitio et al., 2019). Hubungan yang terjalin dengan baik antara masyarakat dengan pemerintah berpengaruh terhadap pembangunan daerah (Ayu \& Purnamasari, 2018). Oleh karena itu, kemajuan pembangunan suatu daerah merupakan tugas dan tanggung jawab bersama.

Keberadaan masyarakat Bulukumba di daerah kabupaten dan kota Kalimantan Timur secara langsung dan tidak langsung telah memberikan sumbangsih dalam berbagai 
bidang pembangunan di Kalimantan Timur. Menurut informasi awal yang diperoleh dari berbagai sumber bahwa masyarakat Bulukumba yang berdomisili di Kalimantan Timur telah banyak sukses dalam bidang keahlian dan pekerjaannya seperti bidang pertanian, peternakan, perkebunan, pemerintahan, dan bidang lainnya. Berdasarkan hal tersebut, maka dilaksanakan suatu penelitian yang bertujuan untuk memberikan informasi tentang partisipasi masyarakat Bulukumba dalam pembangunan daerah di Kalimantan Timur.

\section{METODE PENELITIAN}

Penelitian ini jenis kualitatif deskriptif yang merupakan studi tanpa analisis statistik (Bilgin, 2016) menggunakan desain fenomenologi (Tuksel \& Yildirim, 2015) untuk mendeskripsikan sebuah fenomena (Helaluddin, 2018) tentang partisipasi masyarakat Bulukumba dalam pembangunan daerah berdasarkan pengalamannya selama tinggal di Kalimantan Timur. Populasi adalah masyarakat asal Kabupaten Bulukumba Provinsi Sulawesi Selatan yang terdata dalam Whatsapp group sejak Februari hingga pertengahan Maret 2021 dan berdomisili di Provinsi Kalimantan Timur sebanyak 162 kepala keluarga. Sampel penelitian adalah kepala keluarga atau perwakilan penghuni dalam satu rumah yang berdomisili di wilayah Kalimantan Timur sebanyak 60 orang yang dipilih secara Accidental Sampling. Pengumpulan data menggunakan kuesioner secara online dalam bentuk Google form dan disebarkan kepada responden melalui media sosial Whatsapp Group dan dianalisis secara deskriptif serta disajikan dalam bentuk tabel frekuensi dan grafik disertai narasi. Informan penelitian diperlukan untuk memperdalam informasi yang dibutuhkan dan dipilih 3 informan yakni Ketua Dewan Perwakilan Wilayah Kerukunan Keluarga Bulukumba (DPW KKB) Kalimantan Timur, Pemerintah Kalimantan Timur, dan Pemerintah Kabupaten Bulukumba. Teknik pengumpulan data adalah wawancara mendalam menggunakan pedoman wawancara dan selanjutnya dianalisis secara kualitatif (Matthew et al., 2014). Pengumpulan informasi terhadap informan dilaksanakan pada masa pandemi COVID-19 sehingga menerapkan protokol kesehatan yaitu memakai menjaga jarak, mencuci tangan pakai sabun atau cairan pembersih tangan (hand sanitizer), dan memakai masker.

\section{HASIL PENELITIAN DAN PEMBAHASAN}

Pengumpulan data dilakukan secara online menggunakan Google form selama Februari-Maret 2021 dan sebanyak 60 orang yang berhasil mengisi kuesioner tersebut. Hal ini dilakukan karena masyarakat Bulukumba bertempat tinggal di Kalimantan Timur tidak berada di satu kabupaten/kota saja tetapi menyebar di kabupaten/kota sehingga sulit dilakukan penjangkauan langsung. Selain itu, pengumpulan data dilakukan pada masa pandemi COVID-19 sehingga mengalami keterbatasan dalam melakukan kunjungan langsung ke daerah tempat tinggal responden.

Masyarakat Bulukumba yang berdomisili di Kalimantan Timur memiliki latar belakang pendidikan dan jenis pekerjaan yang berbeda-beda. Hal tersebut dapat dilihat pada tabel 1 tentang karakteristik responden berdasarkan tingkat pendidikan dan jenis pekerjaan sebagai berikut: 
Jumal Sosialisasi

Jurnal Hasil Pemikiran, Penelitian, dan Pengembangan

Keilmuan Sosiologi Pendidikan

Vol 8, Nomor 1, Maret 2021

Tabel 1. Karakteristik Responden Berdasarkan Tingkat Pendidikan dan Jenis Pekerjaan

\begin{tabular}{|c|c|c|c|}
\hline Variabel sosial ekonomi & Kriteria & $\mathbf{n}$ & $\%$ \\
\hline \multirow{4}{*}{ Tingkat pendidikan } & SD & 3 & 5 \\
\hline & SMP/sederajat & 4 & 6,7 \\
\hline & SMA/sederajat & 16 & 26,7 \\
\hline & PT/sederajat & 37 & 61,6 \\
\hline \multirow[t]{5}{*}{ Jenis pekerjaan } & Wirausaha/pengusaha & 9 & 15 \\
\hline & Swasta & 19 & 31,7 \\
\hline & PNS & 19 & 31,7 \\
\hline & TNI & 5 & 8,3 \\
\hline & IRT & 8 & 13,3 \\
\hline
\end{tabular}

Sumber : Data Primer, 2021

Pada tabel 1 menunjukkan bahwa tingkat pendidikan responden sebagian besar adalah perguruan tinggi baik jenjang diploma, sarjana, magister, dan doktor sebanyak 61,6 $\%$ dan tingkat pendidikan terendah adalah SD sebanyak $5 \%$. Jenis pekerjaannya didominasi sebagai swasta dan PNS masing-masing 31,7 \% dan terendah sebagai TNI sebanyak $8,3 \%$.

Provinsi Kalimantan Timur merupakan salah satu provinsi di Indonesia yang dikenal dengan daerah kaya sumber daya alam dan tersebar merata di semua kabupaten/kota (Zaini, 2018). Sektor pertambangan merupakan salah satu sumber daya alam potensial di Provinsi Kalimantan Timur dan dapat memberikan dampak positif dan negatif terhadap sosial ekonomi masyarakat (Suharto et al., 2015). Pertumbuhan ekonomi berdampak pada kondisi sosial di Kalimantan Timur (Puspitasari, 2020).

Masyarakat Bulukumba yang berdomisili di Kalimantan Timur menyebar di 9 kabupaten/kota, akan tetapi pada penelitian ini responden yang terlibat hanya pada 8 kabupaten/kota karena hingga penelitian ini dilaksanakan belum ada informasi keberadaan masyarakat Bulukumba di Kabupaten Mahakam Ulu. Tempat tinggal responden di berbagai kabupaten/kota dapat dilihat pada grafik 1 di bawah ini:

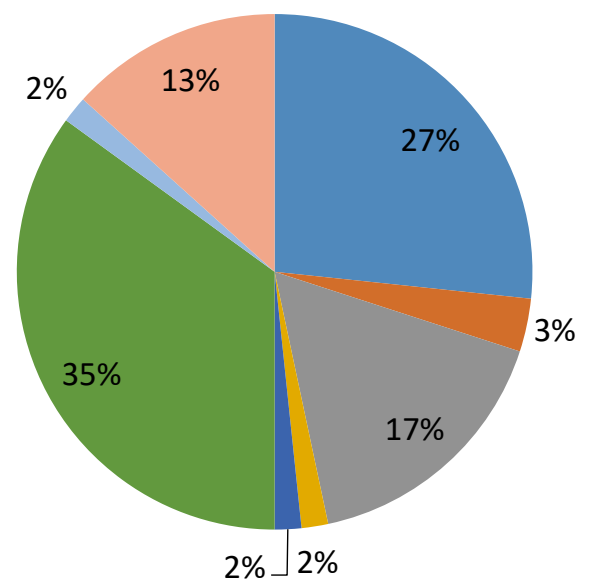

$$
\begin{aligned}
& \text { Balikpapan } \\
& \text { Berau } \\
& \text { Samarinda } \\
& \text { Bontang } \\
& \text { PPU } \\
& \text { Kutim } \\
& \text { Kubar } \\
& \text { Kukar }
\end{aligned}
$$

Grafik 1. Penyebaran responden berdasarkan tempat tinggal (kabupaten/kota) di Kalimantan Timur

Grafik 1 menunjukkan bahwa responden lebih banyak bertempat tinggal di Kabupaten Kutai Timur $35 \%$ disusul Kota Balikpapan $27 \%$ dan Kota Samarinda $17 \%$. 
Sedangkan responden terendah bertempat tinggal di Kota Bontang, Kabupaten Penajam Paser Utara, dan Kabupaten Kutai Barat masing-masing 2\%.

Keberadaan masyarakat Bulukumba yang tersebar di kabupaten/kota Provinsi Kalimantan Timur berdampak pada pertumbuhan penduduk daerah tersebut. Laju pertumbuhan penduduk Kalimantan Timur pada periode 2010-2019 sebesar 1,79 persen. Persebaran penduduk di Kalimantan Timur juga tidak merata pada setiap kabupaten/kota. Pada tahun 2019 penduduk terbanyak Kalimantan Timur berada di Kota Samarinda (23,45 $\%$ ) yang merupakan ibukota provinsi, disusul Kabupaten Kutai Kartanegara (21,12\%) dan Kota Balikpapan (10,11\%) (Puspitasari, 2020).

Selain faktor sosial ekonomi masyarakat, faktor dukungan pemerintah juga mempengaruhi keterlibatan masyarakat dalam pembangunan suatu daerah. Dukungan pemerintah daerah dapat dilakukan dalam berbagai bentuk seperti memberikan kesempatan kepada masyarakat untuk sumbangsih pemikiran mereka dalam penyusunan rencana pembangunan daerah (Surahmi \& Farid, 2018). Selain itu, pemerintah daerah perlu melibatkan dan partisipasi semua unsur masyarakat dalam setiap tahapan program pembangunan sehingga masyarakat memiliki tingkat penerimaan atau akseptabilitas yang tinggi terhadap program pembangunan tersebut (Abady, 2013).

Kesempatan masyarakat Bulukumba untuk berpartisipasi dalam pembangunan daerah di Kalimantan Timur begitu terbuka dan tidak ada diskriminasi. Tingkat partisipasi masyarakat dikategorikan menjadi baik, cukup baik, dan kurang baik (Ardieansyah, 2014). Tingkat partisipasi responden tersebut dapat dilihat pada tabel 2 berikut :

Tabel 2. Tingkat Partisipasi Responden dalam Pembangunan Daerah di Kalimantan Timur

\begin{tabular}{llcc}
\hline Variabel & \multicolumn{1}{c}{ Kriteria } & n & \% \\
\hline Tingkat Partisipasi & Baik & 43 & 71,7 \\
& Cukup baik & 9 & 15 \\
& Kurang baik & 8 & 13,3 \\
\hline
\end{tabular}

Sumber : Data Primer, 2021

Pada tabel 2 menunjukkan bahwa sebagian besar responden $(71,7 \%)$ telah berpartisipasi secara baik dalam pembangunan daerah di Kalimantan Timur. Terdapat 15 $\%$ yang berpatisipasi cukup baik, dan partisipasi yang kurang baik 13,3\%. Masyarakat Bulukumba yang berdomisili di Kalimantan Timur telah berpartisipasi dalam pembangunan daerah dengan berbagai bentuk kegiatan seperti sumbangsih pemikiran dan dilibatkan pada saat penyusunan perencanaan pembangunan. Selain itu, masyarakat Bulukumba juga banyak terlibat secara langsung dalam pelaksanaan pembangunan.

Tingkat partisipasi masyarakat Bulukumba dalam pembangunan di Kalimantan Timur juga disampaikan salah seorang informan yang merupakan Ketua Kerukunan Keluarga Bulukumba (KKB) Kalimantan Timur dalam kutipan hasil wawancara sebagai berikut:

“.....masyarakat Bulukumba sudah banyak terlibat baik langsung dan tidak langsung dalam pembangunan di Kalimantan Timur. Banyak orang Bulukumba yang sukses dalam perantauannya karena mereka ahli di bidangnya masingmasing. Ada yang jadi pengusaha, guru, dosen, pejabat pemerintahan dan lainnya....." (AA, Ketua KKB Kaltim)

Partisipasi masyarakat dalam pembangunan dapat terwujud karena adanya dukungan pemerintah setempat. Masyarakat Bulukumba yang berdomisili di Kalimantan Timur diberikan kesempatan terlibat dalam pembangunan. Hal ini berdasarkan kutipan hasil wawancara terhadap Pemerintah Provinsi Kalimantan Timur sebagai berikut : 
“.....semua masyarakat di Kalimantan Timur diberikan kesempatan yang sama dalam pembangunan termasuk masyarakat Bulukumba yang bertempat tinggal di Kalimantan Timur....” (HM, Pemerintah Provinsi Kaltim)

Selain dukungan pemerintah setempat, dukungan lainnya juga berasal dari Pemerintah Kabupaten Bulukumba terhadap masyarakat Bulukumba di perantauan yang dibuktikan dengan kunjungan dan silaturahmi pihak pemerintah Kabupaten Bulukumba pada saat setiap acara yang diselenggarakan oleh Kerukunan Keluarga Bulukumba Kalimantan Timur.

“.....Pemerintah Kabupaten Bulukumba berupaya untuk selalu hadir pada setiap kegiatan yang diselenggarakan oleh warga Bulukumba dan mendukung warganya agar terlibat dalam pembangunan daerah dimana pun berada....." (EM, Pemerintah Kabupaten Bulukumba)

Partisipasi masyarakat Bulukumba dalam pembangunan daerah Kalimantan Timur tidak terlepas dari falsafah hidup orang Bulukumba yakni memegang dan melaksanakan prinsip "tajam 3 ujung" dimana pun berada. Hal tersebut disampaikan oleh informan seperti pada kutipan hasil wawancara berikut :

“.....masyarakat Bulukumba memiliki dan melaksanakan prinsip hidup dimana pun berada yang dikenal dengan tajam 3 ujungnya...., 3 tajam tersebut yaitu tajam ujung badiknya artinya mereka memiliki sifat pemberani dalam berbagai hal yang positif seperti berani membuka usaha, berani menghadapi tantangan hidup, berani berjuang dalam kebenaran.....,yang kedua tajam ujung lidahnya artinya mampu mengemukakan pendapat, dan hal ini terbukti banyak warga Bulukumba yang jadi guru, dosen, pemuka agama, diplomat.....Ketiga tajam ujung "itunya" (maksudnya alat kelamin) artinya dengan "itunya" warga Bulukumba bisa menikah dengan penduduk Kaltim dan berkembang biak bahkan menetap di Kaltim....." (AA, Ketua $K K B)$

Selain mengenal "tajam 3 ujung", masyarakat Bulukumba juga mengenal "Pasang ri Kajang" (Kajang merupakan salah satu kecamatan di Kabupaten Bulukumba) yang dijadikan sebagai pedoman hidup bagi manusia baik itu dalam aspek sosial, religi, budaya maupun lingkungan. Pesan-pesan tersebut antara lain manyu' siparampe tallang sipahua' (menolong dari bahaya terseret hanyut dan tenggelam) yang berarti perlunya gotong royong dan saling menolong dalam hal kesulitan dan saling membantu dalam kebaikan juga sebagai makhluk sosial perlu saling menghargai dan tenggang rasa satu sama lain. Pesan lainnya anrai-anrai pammarentah anrai tokki, kalau-kalauki pammarentah kalau tokki (jika pemerintah bergeser ke arah barat maupun timur maka kita wajib mengikutinya) yang berarti taat kepada pemerintah dan melaksanakan segala aturan-aturan yang dibuat oleh pemerintah (Asyrafunnisa \& Andi Tenri Abeng, 2019).

Pedoman hidup tersebut diterapkan oleh masyarakat Bulukumba dimana pun berada. Masyarakat Bulukumba memahami bahwa partisipasi dalam pembangunan sesuai amanat undang-undang harus dilakukan. Masyarakat dapat berpartisipasi secara aktif dalam pembangunan daerah pada semua tahapan yaitu perencanaan, pelaksanaan dan evaluasi (Laily, 2015). Kemajuan pembangunan daerah sangat ditentukan bagaimana partisipasi masyarakatnya dalam setiap tahapan tersebut. Pada tahapan perencanaan pembangunan, masyarakat dapat dilibatkan dalam musyawarah perencanaan pembangunan (Musrembang) sehingga masyarakat berpartisipasi aktif dalam proses pengambilan keputusan secara bersama (Latif et al., 2019). 
Partisipasi masyarakat dalam pembangunan dapat berupa buah pemikiran, partisipasi keterampilan, partisipasi tenaga, partisipasi harta benda, dan partisipasi uang (Pangemanan, 2017). Masyarakat dapat berpartisipasi dalam pembangunan sesuai dengan kemampuan yang dimilikinya. Hal ini berarti pula bahwa kesempatan masyarakat untuk terlibat dalam pembangunan disesuikan dengan bidang keahliannya masing-masing.

Masih ditemukan masyarakat Bulukumba yang kurang berpartisipasi dalam pembangunan daerah di Kalimantan Timur. Kurangnya partisipasi masyarakat dalam pembangunan dapat disebabkan berbagai hal antara lain masyarakat belum memahami pentingnya partisipasi masyarakat dalam pembangunan (Hardianti, 2017), kemampuan yang belum memadai dimiliki masyarakat dalam melaksanakan perencanaan partisipatif (Henry, 2014). Oleh karena itu, dibutuhkan sosialisasi dari pihak pemerintah kepada masyarakat tentang pentingnya partisipasi masyarakat dalam pembangunan daerah (Mau, 2015). Selain itu, pentingnya dukungan tokoh masyarakat intelektual dalam membantu pemerintah mensosialisasikan pentingnya partisipasi masyarakat dalam pembangunan (Porawouw, 2016).

Pembangunan daerah yang baik dilaksanakan secara patisipatif sesuai amanah Undang-undang Nomor 6 Tahun 2014 (Dari \& Ayat, 2014). Hal ini dimaksudkan agar pembangunan yang dilakukan benar-benar bermanfaat bagi seluruh warga yang ada di daerah tersebut. Akan tetapi, masih ditemukan daerah di Indonesia yang belum mampu melaksanakan amanah tersebut misalnya melaksanakan perencanaan pembangunan tanpa melibatkan masyarakat sehingga pembangunan desa tidak dapat dirasakan oleh semua lapisan masyarakat. Oleh karena itu, diperlukan upaya untuk mewujudkan perencanaan pembangunan partisipatif melalui berbagai kegiatan seperti pelatihan perencanaan, penganggaran dan evaluasi hasil pembangunan daerah dengan melibatkan perwakilan dari seluruh komponen masyarakat dan pemerintah daerah (Susetiawan et al., 2018).

Pembangunan daerah bukan hanya menjadi tanggung jawab pemerintah, akan tetapi dibutuhkan partisipasi seluruh komponen masyarakat di saerah tersebut. Partisipasi dari masyarakat dalam pembangunan daerah merupakan salah satu pertanda bahwa masyarakat bukan hanya hadir sebagai objek pembangunan tetapi dapat menjadi subjek pembangunan daerah. Oleh karena itu, pemerintah dan seluruh komponen masyarakat dapat berkolaborasi dan bekerja sama pada semua tahapan pembangunan baik tahapan perencanaan, pelaksanaan maupun evaluasi.

\section{PENUTUP}

Masyarakat Bulukumba tersebar menetap di semua kabupaten/kota Provinsi Kalimantan Timur. Sebagian besar masyarakat Bulukumba telah berpartisipasi dengan baik dalam pembangunan daerah di Kalimantan Timur. Hal ini dibuktikan dengan banyaknya masyarakat Bulukumba yang sudah terlibat secara langsung dan tidak langsung dalam pembangunan daerah. Selain itu, masyarakat Bulukumba aktif dalam pembangunan daerah karena adanya dukungan pemerintah Provinsi Kalimantan Timur dan Pemerintah Kabupaten Bulukumba. Masih ditemukan masyarakat yang kurang berpartisipasi dalam pembangunan karena berbagai faktor antara lain kurangnya pemahaman masyarakat tentang pentingnya pembangunan partisipatif. Oleh karena itu, diperlukan kegiatan sosialisasi secara aktif dari pihak pemerintah daerah dan seluruh komponen masyarakat tentang pentingnya partisipasi masyarakat demi terwujudnya pembangunan daerah yang maju dan berkelanjutan. 
Jumal Sosiafisasi

Jurnal Hasil Pemikiran, Penelitian, dan Pengembangan

Keilmuan Sosiologi Pendidifikan

Vol 8, Nomor 1, Maret 2021

\section{DAFTAR PUSTAKA}

Abady, A. P. (2013). Perencanaan partisipatif dalam pembangunan daerah. Otoritas: Jurnal Ilmu Pemerintahan, 3(1).

Ardieansyah, W. (2014). Analisis Partisipasi Masyarakat dalam Pembangunan di Desa Makeruh Kecamatan Rupat Kabupaten Bengkalis. 259-273.

Asyrafunnisa, \& Andi Tenri Abeng. (2019). Peran Pasang Ri Kajang Dalam Kebudayaan Masyarakat Kajang Kabupaten Bulukumba ( Studi Etnografi). Jurnal Ecosystem, 19(April), 54-60.

Dari, D., \& Ayat, P. B. (2014). Undang-Undang Nomor 6 Tahun 2014 Tentang Desa Dilihat Dari Pasal 18 B Ayat 2 Uud 1945. Undang-Undang Nomor 6 Tahun 2014 Tentang Desa Dilihat Dari Pasal 18 B Ayat 2 Uud 1945, 43(1), 149-159. https://doi.org/10.14710/mmh.43.1.2014.149-159

Hardianti, S. (2017). Partisipasi Masyarakat Dalam Pembangunan Infrastruktur Desa (Program Alokasi Dana Desa Di Desa Buntongi Kecamatan Ampana Kota). Katalogis, 5(1), 120-126.

Henry. (2014). Partisipasi Masyarakat Dalam Perencanaan Pembangunan (Studi Kasus Pada Kecamatan Sidikalang Kabupaten Dairi). Jurnal Administrasi Publik, Volume 2(Desember 2014), 118.

Laily, E. I. N. (2015). Partisipasi masyarakat dalam perencanaan pembangunan partisipatif," kebijakan dan manajemen publik. Kebijakan Dan Manajemen Publik, 3(3), 186-190.

Latif, A., Rusdi, M., Mustanir, A., \& Sutrisno, M. (2019). Partisipasi Masyarakat Dalam Pembangunan Infrastruktur Di Desa Timoreng Panua Kecamatan Panca Rijang Kabupaten Sidenreng Rappang Dosen Ilmu Pemerintahan Stisip Muhammadiyah Rappang Dosen Ilmu Administrasi Negara Stisip Muhammadiyah Rappang 5). Jurnal MODERAT, 5(1), 1-15.

Mau, J. A. (2015). Peran Komunikasi Pemerintahan Terhadap Peningkatan Partisipasi Masyarakat Dalam Pembangunan Bersumber Anggaran Pembiayaan Negara. JISIP: Jurnal Ilmu Sosial Dan Ilmu Politik, 4(2), 339-341.

Pangemanan, S. (2017). PARTISIPASI MASYARAKAT DALAM PEMBANGUNAN DESA (Studi di Desa Sinsingon Barat Kecamatan Passi Timur Kabupaten Bolaang Mongondow). Jurnal Eksekutif, 1(1).

Porawouw, R. (2016). Peran Tokoh Masyarakat Dalam Meningkatkan Partisipasi Pembangunan. Politico, 3(1), 1-17.

Puspitasari, L. (2020). Analisis Pertumbuhan Ekonomi dan Pengangguran Terhadap Kemiskinan (Studi Kasus di Provinsi Kalimantan Timur). ECO-BUILD JOURNAL, 4(2), 36-43.

Suharto, R. B., Hilmawan, R., \& Yudaruddin, R. (2015). Sumber Daya Alam Untuk Kesejahteraan Penduduk Lokal : Studi Analisis Dampak Pertambangan Batu Bara Di Empat Kecamatan Area Kalimantan Timur, Indonesia. Jurnal Organisasi Dan Manajemen, Volume 11, Nomor 2, 127-137.

Surahmi, A., \& Farid, H. M. (2018). DUAMPANUA KABUPATEN PINRANG Communication Strategy in Encouraging People' $s$ Participation toward Development in Duampanua Subdistrict, Pinrang Regency Pembangunan merupakan suatu proses pembaharuan yang kontinyu dan terus Usaha pembaharuan untuk mendapa. 7(2), 232-239.

Susetiawan, S., Mulyono, D., \& Roniardian, M. Y. (2018). Penguatan Peran Warga 
Jumal Sosialisasi

Jurnal Hasil Pemikiran, Penelitian, dan Pengembangan

Keilmuan Sosiologi Pendidikan

Vol 8, Nomor 1, Maret 2021

Masyarakat Dalam Perencanaan, Penganggaran, dan Evaluasi Hasil Pembangunan Desa. Jurnal Pengabdian Kepada Masyarakat, 4(1), 109. https://doi.org/10.22146/jpkm.27512

Zaini, A. (2018). Pengaruh Kekayaan Sumberdaya Alam Batubara Terhadap Ketimpangan Pendapatan di Provinsi Kalimantan Timur. Jurnal Borneo Administrator, 13(2), 111130. https://doi.org/10.24258/jba.v13i2.309 